\title{
Pattern of serum transaminases in enteric fever patients attending Ebonyi State University Teaching Hospital, Abakaliki
}

\author{
Edeogu Oswald CHUKS ${ }^{1}$ and Nwosu Zeribe CHIKE ${ }^{2 *}$ \\ ${ }^{I}$ Dept. of Medical Biochemistry, College of Medicine and Health Sciences, Ebonyi State University, \\ Abakaliki, Nigeria. \\ ${ }^{2}$ Chemical Pathology Unit, Department of Laboratory Services, Ebonyi State University Teaching Hospital, \\ Abakaliki, Ebonyi State, Nigeria. \\ *Corresponding author,E-mail: zeribechike@yahoo.com
}

\begin{abstract}
Enteric fever has been associated with adverse multiple-organs perturbation with the liver proposed to be most remarkably affected. In this study, the influence of enteric fever on transaminases [aspartate transaminase (AST), and alanine transaminase (ALT)] was studied using a total of 116 subjects comprising of 55 enteric fever patients (age $=27.19 \pm 8.05$ years) and 61 (age $=26.3 \pm 7.44$ years) apparently healthy control individuals. The enzyme activities were measured spectrophotometrically by Reitman-Frankel Methodology. The result showed that the level of aspartate transaminases in the typhoid patients was $41.56 \pm 18.67 \mathrm{U} / \mathrm{l}$, and significantly higher $(P<0.05)$ than that $(23.2 \pm 13.07 \mathrm{U} / \mathrm{l})$ of the healthy controls, while the patient's alanine transaminases activity was $20.89 \pm 9.25 \mathrm{U} / 1$ and as well higher $(P<0.05)$ than $7.06 \pm 3.54 \mathrm{U} / 1$ for the controls. An evaluation of gender related difference in the activities of the transaminases between enteric fever patients and the controls as well showed the activity of aspartate transaminase to be higher $(P<0.05)$ in male $(\mathrm{n}=30$, $36.57 \pm 19.8 \mathrm{U} / \mathrm{l})$ and female $(\mathrm{n}=25,47.56 \pm 15.52 \mathrm{U} / \mathrm{l})$ patients than in the controls males $(\mathrm{n}=26,26.61 \pm 14.79$ $\mathrm{U} / \mathrm{l})$ and females $(\mathrm{n}=35,20.7 \pm 11.18 \mathrm{U} / \mathrm{l})$, while alanine transaminase was as well higher $(P<0.05)$ in male $(23.43 \pm 11.57 \mathrm{U} / \mathrm{l})$ and female $(17.84 \pm 3.64 \mathrm{U} / \mathrm{l})$ patients than in healthy control males $(6.48 \pm 3.37 \mathrm{U} / \mathrm{l})$ and females $(7.49 \pm 3.66 \mathrm{U} / \mathrm{l})$. We opine that transaminases might be accessible markers of hepatic involvement in enteric fever, its estimation should be widely adopted in the diagnostic and prognostic management of affected patients.

(C) 2010 International Formulae Group. All rights reserved.
\end{abstract}

Keywords: Enteric fever, multiple-organs, markers, liver, management

\section{INTRODUCTION}

Enteric fever is an acute systemic febrile illness usually caused by Salmonella enterica serotypes Typhi, Paratyphi A, Paratyphi B and Paratyphi C (Parry, 2005). The World Health Organization identifies typhoid as a serious public health problem with its incidence being highest in children and young adults between 5 and 19 years old (WHO, 2007). Enteric fever is a widely prevalent disease in several other tropical countries where standards of personal hygiene and sanitation are poor, and is now being associated with other salmonella strains (Sarnighausen et al., 1999; Ghadage and Bal, 2009). For instance, Ghadage and Bal (2009) 
recently reported a case of enteric fever caused by Salmonella weltevreden in a four year old Indian.

Enteric fever is associated with a sustained fever, profuse sweating, gastroenteritic, rash, diarrhoea, and malaise. Constipation is often present, with hepatosplenomegaly and the associated elevation of liver transaminases. Jamil et al. (2004) reported that most frequent symptoms include fever, vomiting, abdominal pain, myalgia, cough, diarrhea and headache, and opined that the most suggestive of the diagnosis of enteric fever included a low-tonormal white cells count, along with thrombocytopenia, elevated alanine aminotrasferase and gamma glutamyl transpeptidase, and proteinuria. In a highly extensive review, Amacher (1998) stated that of the various laboratory markers for hepatic injury, serum transaminases, especially ALT are the most important indicators for studies, noting that hepatocellular damage with the subsequent disruption of the plasma membrane account for the leakage of such enzymes as ALT and AST into the bloodstream.

This study was aimed at unraveling hepatocellular response in enteric fever using aminotransferases, and thus to assess the usefulness of the enzyme levels in diagnosis of enteric fever.

\section{MATERIALS AND METHODS Study population}

A total of 116 subjects consisting of fifty five (55) enteric fever patients, and 61 apparently healthy controls aged between 5 to 44 years, all resident in Abakaliki, Ebonyi State, were recruited for this study. Enteric fever patients were randomly selected from patients from whom Salmonella spp. were isolated from their blood samples upon culture, along side raised Salmonella antibody titre in their sera. These subjects were outpatients in Ebonyi State University Teaching Hospital, while the control subjects were clinical students of the teaching hospital. Male subjects were 30 and 26 for the patients and healthy controls, while the females were 25 and 35 for the patients and controls respectively. The exclusion criteria were subjects with previous history of hepatitis, cirrhosis, pregnancy, preeclampsia, or musculoskeletal diseases.

\section{Ethical consideration}

Ethical approval was gotten from the Hospital's Research Ethics Committee, while all the subjects were enlightened on the relevance of the study.

\section{Sample collection and storage}

About $5 \mathrm{ml}$ of blood was collected from each of the study subjects using $5 \mathrm{ml}$ syringe. The sample was subsequently transferred into borosilicate tube and allowed to clot and retract. This was subsequently centrifuged and the serum used for analysis the same day. Samples that were not analyzed the same day for any reason were stored frozen $\left(-4{ }^{\circ} \mathrm{C}\right)$, but no sample was allowed to stay beyond 48 hours from the time of collection.

\section{Laboratory analysis}

The transaminases were estimated using the Reitman and Frankel Methodology (1957). Transaminases (alanine transaminases and aspartate transaminases) are involved in transamination reaction, a process whereby an amino group is transferred from an amino acid to a keto-acid, forming a new amino acid (glutamate) and a keto acid. The principle of the tests involves the formation of oxaloacetate hydrazone and pyruvate hydrazone by the reaction of oxaloacetate and pyruvate (products of transamination reactions catalysed by aspartate transaminase and alanine transaminase respectively) with 2, 4dinitrophenylhydrazine respectively. The absorbance of the colour developed in each of the reaction mixture was read at a wavelength of $540 \mathrm{~nm}$.

\section{Statistical analysis}

All values were presented as mean \pm SD after analysis using Biostat 2008 software 
v5.13 running in Windows XP operating system. The statistical method used was mainly analysis of variance. Statistically significant values were accepted at $P<0.05$.

\section{RESULTS AND DISCUSSION}

The influence of enteric fever on transaminases [aspartate transaminase (AST), and alanine transaminase (ALT)] was studied using a total of 116 subjects comprising of 55 typhoid fever (age $=27.19 \pm 8.05$ years) and 61 (age $=26.3 \pm 7.44$ years) apparently healthy control individuals. The results of the study are presented in Tables 1 and 2 .

Table 1 is a comparison of the mean values of transaminases in enteric fever and apparently healthy control subjects. The level of aspartate transaminases in the patients was $41.56 \pm 18.67 \mathrm{U} / \mathrm{l}$, and significantly higher $(P<0.05)$ than that $(23.2 \pm 13.07 \mathrm{U} / \mathrm{l})$ of the healthy controls, while the patient's alanine transaminases activity was $20.89 \pm 9.25 \mathrm{U} / \mathrm{l}$ and as well higher $(P<0.05)$ than $7.06 \pm 3.54$ $\mathrm{U} / \mathrm{l}$ for the controls.
Table 2 shows an evaluation of gender related difference in the activities of the transaminases between typhoid patients and the controls. The activity of aspartate transaminase was higher $(P<0.05)$ in male $(\mathrm{n}=30,36.57 \pm 19.8 \mathrm{U} / \mathrm{l})$ and female $(\mathrm{n}=25$, $47.56 \pm 15.52 \mathrm{U} / \mathrm{l})$ patients than in the male $(\mathrm{n}=26,26.61 \pm 14.79 \mathrm{U} / \mathrm{l})$ and female $(\mathrm{n}=35$, $20.7 \pm 11.18 \mathrm{U} / \mathrm{l})$ controls. Also, alanine transaminase was higher $(P<0.05)$ in male $(23.43 \pm 11.57 \mathrm{U} / \mathrm{l})$ and female $(17.84 \pm 3.64$ $\mathrm{U} / \mathrm{l})$ patients than in healthy male $(6.48 \pm 3.37$ $\mathrm{U} / \mathrm{l})$ and female $(7.49 \pm 3.66 \mathrm{U} / \mathrm{l})$ controls.

Enteric fever is a growing public health problem, and is associated with significant morbidity and mortality globally, especially among travelers (Steffen et al., 2003; Crump et al., 2004; Basnyat et al., 2005). Various literatures have supported the involvement of multiple organs in enteric fever, ranging from the cardiopulmonary, gastrointestinal, to hepatobiliary manifestations (Garba et al., 2005; Huang and DuPont, 2005).

Table 1: Comparison of the mean values of transaminases in enteric fever patients and apparently healthy control subjects.

\begin{tabular}{lccccc}
\hline \multicolumn{1}{c}{ Study group } & Age (years) & $\begin{array}{c}\text { AST } \\
(\mathbf{U} / \mathbf{I})\end{array}$ & $\begin{array}{c}\text { Confidence } \\
\text { interval }\end{array}$ & $\begin{array}{c}\text { ALT } \\
(\mathbf{U} / \mathbf{l})\end{array}$ & $\begin{array}{c}\text { Confidence } \\
\text { interval }\end{array}$ \\
\hline $\begin{array}{l}\text { Typhoid fever } \\
\text { patients } \\
\mathrm{n}=55\end{array}$ & $27.19 \pm 8.05$ & $41.56 \pm 18.67$ & $36.52-46.61$ & $20.89 \pm 9.25$ & $18.39-23.39$ \\
$\begin{array}{l}\text { Healthy controls } \\
\mathrm{n}=61\end{array}$ & $26.3 \pm 7.44$ & $23.2 \pm 13.07$ & $18.78-30.68$ & $7.06 \pm 3.54$ & $4.94-8.69$ \\
\begin{tabular}{l}
$P$-values \\
\hline
\end{tabular} & $P>0.05$ & $P<0.05$ & - & $P<0.05$ & - \\
\hline
\end{tabular}

Table 2: Evaluation of gender related difference in the activities of the transaminases between enteric fever patients and the controls.

\begin{tabular}{lcccc}
\hline \multirow{2}{*}{ Study group } & \multicolumn{2}{c}{$\begin{array}{c}\text { AST } \\
\text { (U/L) }\end{array}$} & \multicolumn{2}{c}{$\begin{array}{c}\text { ALT } \\
\text { (U/L) }\end{array}$} \\
\cline { 2 - 5 } & Males & Females & Males & Females \\
\hline Enteric fever & $36.57 \pm 19.82$ & $47.56+15.52$ & $23.43 \pm 11.57$ & $17.84 \pm 3.64$ \\
patients & $(\overline{30})$ & $(\overline{25})$ & $(\overline{30})$ & $(2 \overline{5})$ \\
Healthy controls & $26.61 \pm 14.79$ & $20.7 \pm 11.18$ & $6.48 \pm 3.37$ & $7.49 \pm 3.66$ \\
& $(\overline{26})$ & $(\overline{35})$ & $(\overline{26})$ & $(\overline{35})$ \\
$P$-values & $P<0.05$ & $P<0.05$ & $P<0.05$ & $P<0.05$ \\
\hline
\end{tabular}

Numbers in bracket represent the number of subjects of the same sex for each parameter and study group. 
In this study, the influence of enteric fever on serum aminotransferases as an assessment of hepatocellular involvement was evaluated, with the outcome showing consistently higher transaminase activities in the patients as observed in previous studies (Khosla et al., 1987; Giboney, 2005; Abro et al., 2009). Chalkias et al. (2008) noted a case of very high level of aspartate transaminase and alanine transaminase in an enteric fever subject, and highlighted a spread of the disease in developed countries. A possible explanation for the raised transaminases could be hepatocellular injury occasioned by the enterotoxins produced by the salmonella septicemia, as Amacher (1998) noted that hepatocellular damage with the subsequent disruption of the plasma membrane accounted for the leakage of such enzymes as ALT and AST into the bloodstream. Khosla et al. (1987) highlighted that enteric fever is associated with a spectrum of hepatic injury, and showed the incidence of hepatic dysfunction to be as high as $55 \%$ in their study population. They asserted that although hepatic manifestations in enteric fever are mild, a few infected patients might show manifestations similar to that of viral hepatitis, amebic liver disease, and malaria complicated with hyperbilirubinemia.

Giboney (2005) stated that raised level of transaminases as seen in these subjects is a common laboratory picture especially in people who are asymptomatic for liver diseases, while Kudalkar et al. (2004) reported a case of an enteric fever patient that did not have raised transaminase level. Thus, limitations due to our inability to obtain detailed clinical history of underlying hepatic dysfunctions underscores the need for further work to be carried out to confirm the diagnostic sensitivity and specificity of transaminases in enteric fever in this study population.

\section{Conclusion}

Awareness of the high prevalence of enteric fever and its associated multi-organs disturbance highlights the need for laboratory investigations that are both specific and sensitive to be employed in the assessment of organ activities. Higher levels of transaminases in enteric fever subjects support its diagnostic usefulness in predicting hepatocellular involvement even though it remains obscure to what extent it does. Thus, Clinicians should request for transaminases estimation in all patients presenting with enteric fever, while other liver function parameters should be compulsorily assayed for those patients having elevated transaminase activity.

\section{REFERENCES}

Abro AH, Abdou AMS, Gangwani JL, Ustadi AM, Younis NJ, Hussaini HS. 2009. Hematological and biochemical changes in typhoid fever. Pak. J. Med. Sci., 25(2): 166-171.

Amacher DE. 1998. Serum transaminase elevations as indicators of hepatic injury following the administration of drugs. Regulatory Toxicol. Pharmacol., 27: 119-130.

Basnyat B, Maskey AP, Zimmerman MD, Murdoch DR. 2005. Enteric (typhoid) fever in travelers. Clin. Infectious Dis., 41: 1-6.

Chalkias A, Anastasopoulos D, Tsiaglis S. 2008. Enteric fever due to Salmonella Paratyphi $A$ in Greece: a case report. Cases J., 1: 403.

Crump JA, Luby SP, Mintz ED. 2004. The global burden of typhoid fever. Bulletin of the World Health Organization; 82: 346-353.

Garba IH, Gatsing D, Awwal, Gadzama J. 2005. Alanine and aspartate transaminases in the serum of acute appendicitis patients before and after surgery. The Internet Journal of Gastroenterology, 4(1).

Ghadage DP, Bal AM. 2009. Enteric fever due to Salmonella weltevreden in a fouryear-old child. Indian J. Med. Sci., 56: 273-275.

Giboney PT. 2005. Mildly elevated liver transaminase levels in the asymptomatic 
patient. Am. Fam. Physician, 71(6): 11051110.

Huang DB, DuPont HL. 2005. Problem pathogen: extra-intestinal complications of salmonella enterica serotype typhi infection. Lancet Infect. Dis., 5: 341-348.

Jamil B, Lashari I, Bhatti S, Hasan RS. 2004. Enteric fever in adult patients: clinical features, outcome and antibiotic susceptibility patterns. Infect. Dis. J. Pakistan, 3: 68-72.

Khosla SN, Singh GP, Trehan VK. 1987. The spectrum of hepatic injury in enteric fever. J. Clin. Pathol., 13: 14-19.

Kudalkar D, Thermidor M, Cunha BA. 2004. Salmonella paratyphi A enteric fever mimicking viral meningitis. J. Crit. Care, 33: 414-416.

Parry CM. 2005. Epidemiological and clinical aspects of human typhoid fever. In 'Salmonella' Infections: Clinical,
Immunological and Molecular Aspects. Mastroeni P, Maskell D (eds). Cambridge University Press: Cambridge; 1-10.

Reitman S, Frankel S. 1957. A colorimetric method for the determination of serum glutamic oxalacetic and glutamic pyruvic transaminases. Am. J. Clin. Pathol., 28: 56-63.

Sarnighausen HE, Bent C, Eickenberg M, Bockemuhl J, Tschape H, Riemann JF. 1999. Typhoid fever due to Salmonella Kapemba infection in an otherwise healthy middle-aged man. J. Clin. Microbiol., 37: 2381-2382.

Steffen R, De Bernardis C, Banos A. 2003. Travel epidemiology - a global perspective. Int. J. Antimicrobial Agents, 21: $89-95$.

WHO. 2007. Typhoid fever http://www.who. int/vaccine_research/diseases/diarrhoeal/e n/index 7.html.Retrieved on 2009-07-20. 